\title{
A Complexity Architecture for Information Technologies: A Three-Year Didactic Experiment
}

\author{
Fernando Sáez Vacas ${ }^{1}$
}

Received April 5, 1988; revised January 25, 1989

\begin{abstract}
One medium-term strategy for helping in the management of complexity is the introduction of a conceptual complexity component in the very centre of university curricula: In very few areas is the growth of complexity as'evident as in the information technologies (ITs), the focus of the work presented in the current paper. We have therefore developed an integrated way of tackling the specific field of information technologies by means of an approach to complexity. The content of this paper describes the guidelines of our research effort, placing an emphasis on informatics. Concepts of complexity based on the system metaphor have been substantially drawn upon in this exercise and are thus presented in some detail. Also described, is a didactic experiment conducted by the author and designed to provide a new and integrating approach to University curricula for future professionals. The students" "discovery" of complexity is the focal point of the experiment. The findings of this effort are encouraging and call for the continuation and expansion of this experiment.
\end{abstract}

KEY WORDS: complexity; information technology; systems engineering; social system:

\section{INTRODUCTION}

General systems approaches have had little success in the field of education. Boulding mentioned this not too long ago when pointing out how some professors of general systems courses usually manage to teach this subject "under an assumed name" (Boulding, 1986). In our case, virtually the contrary has occurred.

Since 1978, the author has succeeded in including in the curriculum of Madrid's Escuela Ténica Superior de Ingenieros de Telecomunicación

\footnotetext{
${ }^{1}$ Department of Telematic Engineering, University of Technology, Madrid, Spain:
} 
(ETSIT) semester courses entitled Cybernetics and Systems Theory 1 and Cybernetics and Systems Theory 2, which later became Cybernetics and Systems Theory, and Systems Engineering. After 7 years of teaching the first course, the contents of which centered on Klir's classical text (Klir, 1969), we received a favorable (albeit somewhat cold) reception. During the 1985-1986 school year the decision was made to change the contents of the course completely, while leaving the name of the course intact.

The new approach of the course centers on the study of information technologies and their likely impact - which is based on studies of complexity. This approach was welcomed by students and proved to be a useful way of introducing the basic concepts of general systems and of encouraging a feeling for systems thinking: in other words, this approach has motivated students at once toward interdisciplinarity and a sociotechnical viewpoint.

The contents of the course in question were organized so as to counterbalance the excessive degree of specialization currently found in informatics curricula [Association for Computing Machinery (ACM), Institute of Electrical and Electronics Engineers (IEEE), and related curricula]. The ETSIT's informatics curriculum also show this trend toward overspecialization. The course contents and the teaching methodology were formulated 4 academic years ago. Enough time has elapsed to make the documentation of this experiment meaningful:

In this paper, I therefore report two important outcomes of this study. First, the classifications, definitions, and related techniques for complexity are presented., Second, a course we developed to incorporate these findings is critically discussed.

Thus, the first part (Sections 2-4) of this article describes how the course contents were selected, structured, and prepared. The second part (Sections 5-7) discusses the bibliography and methodology of the course and presents an evaluation of its successes/failings.

\section{THE NEED FOR, AND SCOPE OF, AN ARCHITECTURAL SCHEME FOR THE COMPLEXITY OF INFORMATION TECHNOLOGIES}

In the "constant changes" of the world in general, and in information technologies.(ITs) in particular, complexity is ever present in various shapes and forms and, thus, poses a variety of difficulties that need to be explicitly addressed.

Our point of departure, then, is the inevitable and growing presence of complexity. This idea is complemented by two other equally important ideas: (a) complexity has negative and positive aspects; and (b) complexity depends 
Table I. A Broad View of the Concept Complexity

Complexity is the name we are giving to the condition of human beings, objects, phenomena, processes, concepts, and feelings because

(a) they are difficult to understand or explain;

(b) their causes, effects, or structure are unknown;

(c) they require either a great deal of information, time, or energy to be described or managed or a huge coordinated effort on the part of persons, equipment, and machinery;

(d) they are subject to a variety of perceptions, interpretations, reactions, and applications that are often contradictory or disconcerting;

(e) they produce effects that are simultaneously desirable and undesirable (or difficult to control);

(f) their behaviour, depending on the case, may be unpredictable, relatively unpredictable, extremely variable, or counterintuitive.

Table II. General Program for Research into Complexity

In artificial systems, what does complexity consist of?

(a) What factors does it depend on?

(b) What shapes does it take?

(c) What are its consequences?'

(d) How does it evolve?

(e) What can be done to prepare for, and to measure and manage it?

(in part) on the observer and on the devices available to the observer to carry out his work.

By initially accepting a broad concept for complexity (see Table I), we set out to design and follow an eclectic program for seeking out and adopting various constructs through which an architectural scheme can be drawn up in the specific field of ITs (and more specifically, informatics). Complexity is undeniably a rapid emerging dimension of ITs, although up to the present it has not been systematically studied except in the branch of computational complexity. Computational complexity is the time it takes to calculate an algorithm, for example, the algorithm that controls the movement of an antenna directed at a satellite for data transmission purposes. There is an elaborate theory on this type of complexity, but it is a drop of water in the vast sea of complexity. For this reason, there is a paucity of organized knowledge suitable for our purposes. We therefore generated our own research program.

Table II presents our general program for areas of research into complexity, although restricting the inquiry to artificial systems is a significant 


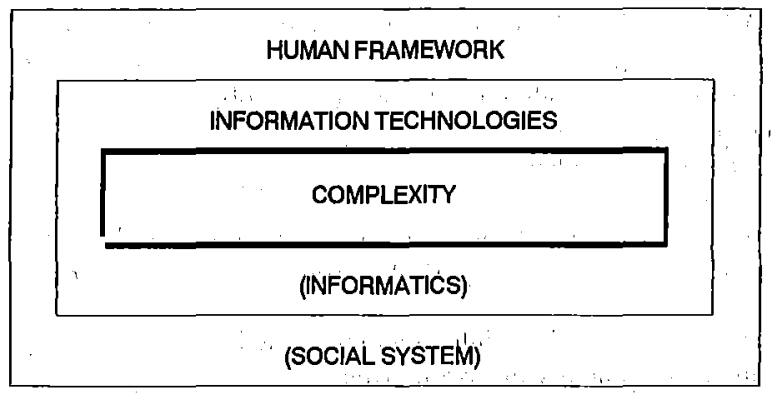

ENGINEEŔING STANDPOINT

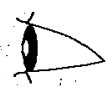

SYSTEM STANDPOINT

Fig. 1. Principal points and criteria for a technical-humanist architecture of complexity of information technologies.

narrowing of the potential application domain. Tables I and II are closely related.

To make the content of Table II operative, we have tailored the questions to the specifics of artificial systems of ITs and have shaped it by means of a set of guidelines defined by the key words "engineering," "system,"2 and "human framework" (see Fig. 1). These key words represent three related points of view that contribute synergetically to the understanding generated through the research program.

Through our efforts to design a technical-humanist architecture of complexity of ITs, we are in fact attempting to establish. a small group of basic "constancy traits" which might contribute to a general systems view of the world.

\section{INTERRELATIONSHIPS BETWEEN THE COMPLEXITY OF THE WORLD AND THE COMPLEXITY OF ITS}

If we wish to consider the complexity of ITs within the human framework, we must necessarily consider the observer in the broadest sense possible. In other words, we must view the complexity of the world as the complexity of the social system. Figure 2 presents this viewpoint by developing various aspects of Fig. 1 in a more dynamic graphic format. The more darkly outlined square reflects our intention to emphasize, for circumstantial reasons, ${ }^{3}$ the more technical and instrumental sides of complexity.

\footnotetext{
${ }^{2}$ We recognize the notion or metaphor of a "system" as the simplest basic complex unit but one which does not exhaust the possibilities of a complexity paradigm, according to Morin (1977). ${ }^{3}$ Madrid's Escuela Técnica Superior de Ingenieros de Telecommunicación (ETSIT) is highly technological in its approach.
} 


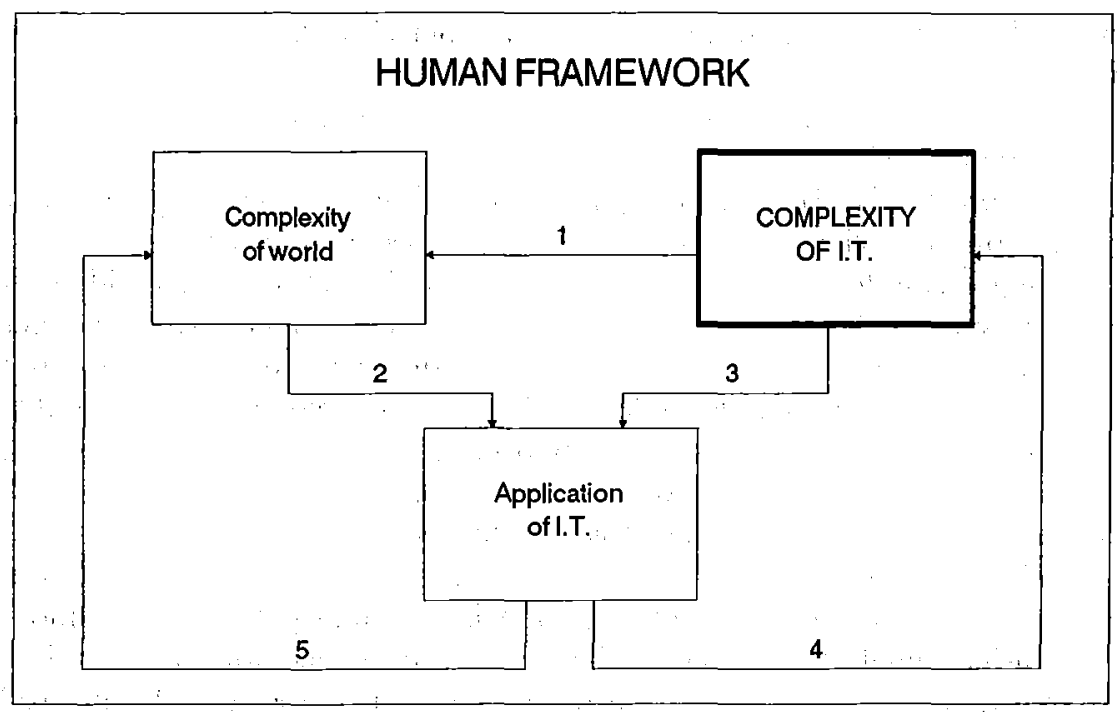

Fig. 2. A dynamic model of overall complexity relationships as a guide to the choice and organization of topics in an educative program.

The arrows indicate the overall relationships and interactions which guide the choice and organization of topics in the program. These are explained below.

Arrow 1 (Fig. 2). Undoubtedly, technological advances have given rise to higher levels of complexity in the world. Its impact on our ability to manage time space, and information is multiplying. The tendency of ITs to move toward mutual integration through the highly active electronification, digitalization, and computerization process under way could give rise to exponential changes in this impact. (Sáes Vacas, 1983; Matsumura, 1983; Bartee, 1985).

Arrow 2 (Fig. 2). This poses the question "What does the complexity of the world consist of?" In particular, the concern is with "what the complexity of the world's institutions consists of", [conceived through the questions in Table II if we accept that the institutions have been modeled as artificial systems in accordance with Simon (1970)]. A pioneer in complexity studies, Simon refers to "artificial" phenomena in the following sense (Simon, 1970): “They are as! they are only because of a system's being molded, by goals or purposes, to the environment in which it lives." Effects such as the instability and the systemic design pattern of institutions, presented by such authors as Beer $(1974,1975)$, Ackoff (1974), and others, have provided us with suitable study guidelines. Also helpful along these same lines are the opinions of social critics inspired by 
nontechnological and, at time, antitechnological feelings, such as Illich (1973), to give one example.

Arrow 3 (Fig. 2). This poses the question "What does the complexity of ITs consist of?"

Arrow 4 (Fig. 2). Our diagram clearly situates complexity in a new dimension, nontrivial knowledge of which becomes a prerequisite for applying technology to the world (Arrow 5). Moreover, it should be a prerequisite for designing or redesigning technologies themselves; in other words, it should project itself as a conceptual base of know-how and techniques for constructing, understanding, and overcoming the inevitable and increasing complexity of information technologies and their effects. One intense field of application in this regard is the design of "natural" human-machine interfaces. Next-generation computers, supposedly to be available in the 1990s, point in the same direction: they will combine maximum performance with conviviality [that is, the ability "to perform more human-like intellectual functions like inference, association and learning, as well as nonnumeric processing of speech, text, graphics and patterns" (Torrero, 1985)].

Arrow 5 (Fig. 2). Finally, a positive aspect is the potential of ITs to help cope with the complexity of the world which, in practical terms, has prompted us to undertake an applied study (typical of engineering) of problems and techniques, so as to turn this potentiality into a reality in specific fields, e.g., office information systems in human organizations (Hirschheim, 1985).

It could be said that the meaning we want to symbolize by the actions of this arrow is that of offsetting, mitigating, or correcting the effects produced by Arrow 1, representing the types of technological intervention that are not guided by a systematic knowledge of complexity.

\section{AN ATTEMPT TO SYNTHESIZE: EXPLORATION, CLASSIFICATION, DEVELOPMENT, AND APPLICATION}

The foregoing is a description of our main ideas that work toward a conceptual remodeling of information technologies based on a broad consideration of complexity. Basically, the study involves reflection and synthesis aimed at identifying, defining, and describing various meaningful types of complexity. These are characterized by certain properties and their respective devices for investigation (always in connection with the human factor and its various interactions with ITs).

In order to illustrate the practical advances of this work, a number of schematic examples (which appear in no particular order and are by no means exhaustive) are given below (for a more extensive documentation see Sàez Vacas, 1987a). 
Table III. Classification and Definition of Types of Complexity and Techniques for Managing Complexity

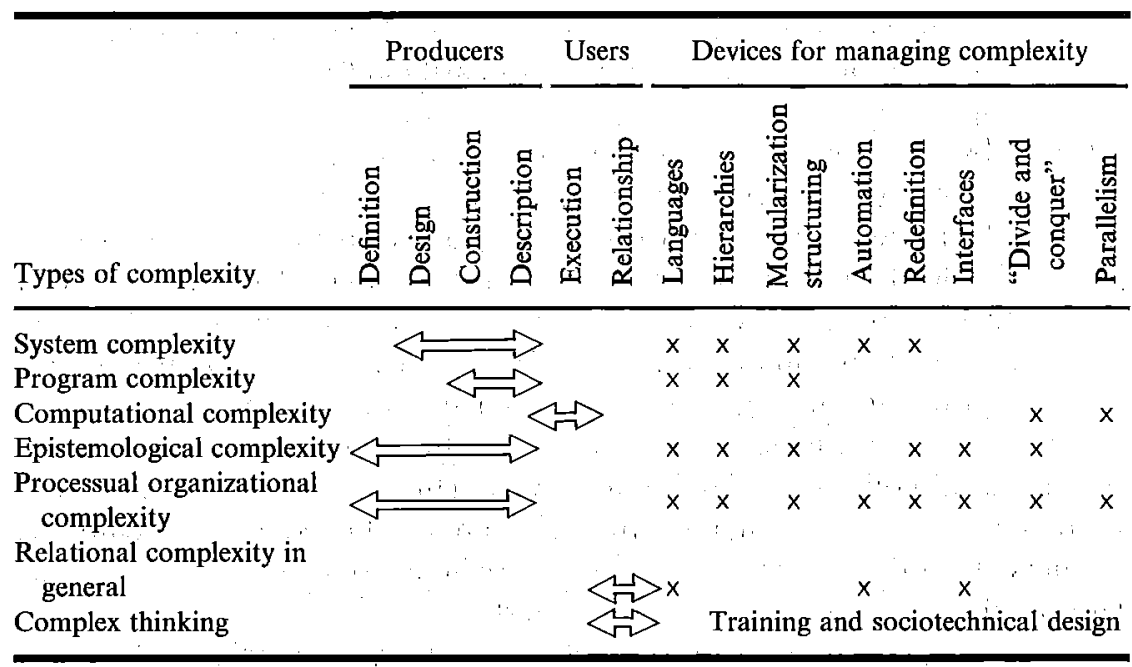

Classification and definition of some of the types of complexity and diverse techniques for managing complexity are given in Table III (the human activities involved are represented by a double arrow). Some comments on this table are given below.

1. Epistemological complexity is the complexity present when passing from the object to the system (according to Ashby, 1956; Klir, 1969).

Processual organizational complexity is the complexity of process coordination and control.

Complex thinking is the complexity created by the mismatching of the user's and the artificial system's "cognitive" processes.

2. Software complexity can be studied by looking at four types of complexity. One good example of this line of reasoning is the Strategic Defense Initiative (SDI) project [see Parnas (1985) in the Appendix]:

- system complexity,

- epistemological complexity,

- organization complexity, and

- computational complexity.

3. There are three levels of complexity in informatics, i.e., there is a broad three-level perspective (see Sáez Vacas, 1983a).

- Level 1: Complexity of a component, e.g., program complexity.

- Level 2: Complexity of a system, e.g., complexity of an integrated circuit, of data-base software, or of a computer network. 
- Level 3: Complexity of an anthropotechnical system-order, logic, and disorder or conflict are all present at the same time. (This last aspect is a hard concept for an IT engineer to perceive because he has been educated primarily under a strictly rationalist paradigm.)

4. Observers can be divided into two large groups: the first group is that of technicians, which we call producers/designers (see Sáez Vacas, 1984) and which, in turn, can be subdivided into smaller groups, should the need arise; the second group is that of users, which can also be broken down into smaller groups. One category of observers that plays an important role in technological innovation processes is that of user-managers and entrepreneurs, for example.

The reader may have the impression that these items seem to be a more or less casual collection of different things. This is also the students' first impression. For this reason, it is extremely important to construct a synthesis and make periodical references relating those items studied during the course with the diagrams presented in Figs. 1 and 2.

Plans have been made to conduct some additional studies with a view to amply justifying embarking on a systematic project for developing the program described in Sections 2, 3, and 4. It is nevertheless difficult to secure economic support for this type of project in Spain.

Let us now see how some of these findings have been incorporated into a course in ITs that aims to overcome difficulties of specialized curricula.

\section{THE DRAWBACKS OF OVERSPECIALIZED TECHNICAL TEACHING}

The inevitable and growing presence of complexity in various forms within technology itself and, in practical application, makes strictly specialized teaching not only incomplete but, in some respects, dangerous and an undeniable source of more complexity.

Complementarily, information technologies are moving increasingly closer toward mutual integration, making it easy to predict that their impact on society will sharpen considerably: These two circumstances make it advisable to devise a broader way to see things, not only on a strictly technical level but also on a sociotechnical level.

In contrast, trends in the educational system for professionals of information technologies and informatics, in particular, seem to be moving in the following directions: (a) toward greater specialization, (b) toward a reduction in systemic approaches, and (c) away from the study of social problems (economic, sociological, psychological, etc.). 
In the author's opinion, these trends should be turned around by incorporating some correction mechanisms into specialized curricula, although we naturally believe that the very architecture of training would actually have to be completely overhauled. The course analyzed herein is a contribution to the design and construction of this type of mechanism, in this case based on the author's conviction that complexity has become an increasingly important dimension of information technologies.

\section{COURSE DESCRIPTION}

The aims of the course are to familiarize the student with a coherent and practical diagram (a form of architecture) of complexity and information technologies.

The openness and scope of this subject, together with the fact that it involves an as yet unstructured field, condition the choice of contents, approach, and working bibliography, and the course's very teaching methodology. Below I provide some information on these aspects of our course.

\subsection{Contents and Working Bibliography}

It is not easy to synthesize the set of concepts developed in class, for it is extensive and involved. As an approximation, we first make a short list of the class contents by category, with a brief explanation of the same. The Appendix presents the working bibliography of first-year students (this very complete bibliography is complemented in class with explanations drawn from other broader reference works). Next we provide a description of the approach, i.e., a description of the dynamic ordering of the subjects dealt with.

It should not be forgotten that this classification is purely conventional. In comparison with the strong interrelationship of the components and their didactic development, it represents nothing more than a static, impoverished view of the contents of the course.

- Informatics complexity. Under this heading fall those matters which, directly or indirectly, deal with the problem of the complexity of informatics systems. References 3, 7 and 15 listed in the Appendix, involve aspects related to software, while reference 14 centers on hardware. Reference 12, the Appendix, provides an overview and proposes a framework in which the discourse on informatics complexity can be integrated. 
- Theory of complexity. A paper written by Klir (5) (see the Appendix) has been the main point of contact with the most abstract aspects of complexity.

- Conviviality, society, men, and machines: Under this heading the course makes use of some reference works dealing with the problems encountered when introducing information technologies, in general (and computers, in particular), into human systems. The reference numbers for these texts are 1, 4, 6, 9, and 13 in the Appendix.

- Information technologies. The subject areas tackled hereunder pertain to the evolution and integration of ITs (information technologies). The texts used for this part of the course include references 8 and 10 in the Appendix and works that describe the areas encompassed under the heading on information technologies (2).

The above description could lead one to believe that the aspects of informatics complexity are reduced to classical computational complexity, to computer programming complexity, or to the very complexity of computers. As stated in Section 1, this is by no means the case because our concept of complexity includes an architecture comprising a variety of types of complexity whose scope and range of pertinent tools are summarised in Table III.

Section 3 and Fig. 2 synthesize the approach of the course, that is, the putting to use and intent of the aforementioned course contents.

\subsection{Methodology}

Didactic methodology has centered primarily on the active participation of students, although the shape this participation takes may vary from one year to the next.

The main features are as follows.

(i) An open working bibliography (see the Appendix) is used. The nature of this openness is reflected, on the one hand, in the broad criteria used in the selection of the bibliography (books, articles from scientific journals, magazine articles, conference papers, technical approaches, humanistic approaches, etc.) and, on the other, by the fact that the bibliography can be updated with new publications written either by experts (an easy feat given the effervescence and evolution of the subject matter at hand) or by the students themselves during the course. For example, the bibliography for the second year was updated by including two essays prepared by two groups of students, one of which was entitled "The Integration of Information Technologies" and the other "Complexity and Computers." Additions to the bibliography for the third year include a paper written by the author (Sáez Vacas, 1987), as well as a paper recently published by Flood (1987), which 
complements Klir's observations ( 5 in the Appendix) remarkably well. Flood goes further than Klir to stress in his approach to complexity the human factors with the Homo sapiens line, which I have found something similar to my third level of complexity [see Section 4 or Sáez Vacas (1983)].

(ii) Classes during which the professor lectures are few, and these are generally limited to subjects of which the students have virtually no knowledge. Instead, the students themselves usually engage in short presentations, debates, and expositions, with many of these exercises being followed up by brief syntheses, clarifications, and further explanations. One important lecture, albeit a difficult one to schedule and gauge properly, involved a major synthesis, integrating the course's concepts, methods, techniques, or viewpoints in an overall picture of interaction.

(iii) There is a concern constantly to relate the contents of this course with the contents of the rest of the curriculum so that the latter are seen in a new light.

(iv) The evaluation of the students' performance is based on a combination of personal assignments (generally carried out in small groups, given the large number of students) and an exam.

\section{COURSE EVALUATION}

Course evaluation is based primarily on confidential questionnaires that the students are asked to fill out.

\subsection{Surveys}

Table IV presents the main numeric findings taken from the surveys conducted during the first 2 school years in question.

Given the somewhat uncommon nature of this course, an additional questionnaire was formulated this last academic year for a dual purpose: (i) to quantify the students' opinion of the real development of the course, as opposed to their idea prior to enrollment (completely erroneous); and (ii) to quantify as well the theoretical-practical profiles of the students' taste and of the course, as seen by the students.

As for the first purpose, the students' degree of final satisfaction with respect to their pre-enrollment opinion of the course was positive or highly positive $75 \%$ of the time and negative or highly negative $15 \%$ of the time $(10 \%$ were neutral). It should be noted that due to organizational factors, inter alia, at ETSIT in Madrid, students lacked valid information about this course, and their decision to enroll in the same was prompted by a wide 
Table IV. Survey Findings

\begin{tabular}{|c|c|c|c|c|c|c|c|c|c|c|}
\hline & \multicolumn{10}{|c|}{ Academic year ${ }^{a}$} \\
\hline & \multirow{2}{*}{\multicolumn{2}{|c|}{$1985-1986^{b}$}} & \multicolumn{4}{|c|}{$1986-1987^{c}$} & \multicolumn{4}{|c|}{$1986-1987^{d}$} \\
\hline & & & \multicolumn{2}{|c|}{$\mathrm{C}$} & \multicolumn{2}{|c|}{ D } & \multicolumn{2}{|c|}{$\mathrm{E}$} & \multicolumn{2}{|c|}{$\mathrm{F}$} \\
\hline & $\begin{array}{c}\mathrm{A} \\
\mu\end{array}$ & $\begin{array}{c}\mathrm{B} \\
\mu\end{array}$ & $\mu$ & $\sigma$ & $\mu$ & $\sigma$ & $\mu$. & $\sigma$ & $\mu$ & $\sigma$ \\
\hline Contents interest & 7.56 & 7.05 & 7.07 & 1.88 & 7.15 & 1.82 & 7.13 & 1.36 & 6.97 & 1.20 \\
\hline Teaching methodology & 6.80 & 6.43 & 7.14 & 1.76 & 7.17 & 1.72 & 7.00 & 1.46 & 5.65 & 1.64 \\
\hline Professor's knowledge of course contents & 9.28 & 8.99 & 8.95 & 0.99 & 8.98 & 0.98 & 8.70 & 0.86 & 7.35 & 1.23 \\
\hline \multirow{4}{*}{$\begin{array}{l}\text { Would you recommend this course to } \\
\text { fellow students coming after you? } \\
\text { Do you think that all students in areas } 3 \\
\text { and } 4 \text { should take this course? }\end{array}$} & & & & & & & & & & \\
\hline & 6.88 & 6.62 & .7 .14 & 2.23 & 7.17 & 2.19 & & & & \\
\hline & & & & & & & & & & \\
\hline & 6.73 & 7.18 & 7.64 & 2.59 & 7.78 & 2.55 & & & & \\
\hline
\end{tabular}

(A) Students attending more than $70 \%$ of the course ( 21 responses). (B) Students attending between $40 \%$ and $70 \%$ of the course (16 responses). (C) Students attending more than $70 \%$ of the course ( 42 responses). (D) Students attending more than $40 \%$ of the course ( 46 responses): (E) Our course. (F) Other courses making up the fifth year of study (fifth level).

${ }^{b}$ The standard deviation was not calculated.

${ }^{c} \mu$, average value; $\sigma$, standard deviation.

${ }^{d}$ Survey for academic year 1986-87 conducted after the year had ended; based on a total of 20 samples.

${ }^{e}$ The ETSITM Studies Program covers six areas of specialization, ranging from radio transmission to microelectronics. Areas 3 and 4 are those whose course work is most directly related to the wide spectrum of informatics. 
Table V. One of the Questions that Appeared in the Additional Questionnaire

"In column one, truthfully indicate your personal preference independently of this course. In column two, rate the course."

\begin{tabular}{|c|c|c|}
\hline & \multicolumn{2}{|c|}{ Perceñtaǵe } \\
\hline & $\begin{array}{c}\text { Personal } \\
\text { preference }\end{array}$ & Course \\
\hline \multirow{4}{*}{$\begin{array}{l}\text { I like a concrete, practical approach } 100 \% \text { of the time. } \\
\text { I like a general, theoretical approach } 25 \% \text { of the time } \\
\text { and a concrete, practical approach } 75 \% \text { of the time. } \\
\text { I like a general, theoretical approach } 50 \% \text { of the time } \\
\text { and a concrete, practical approach the other } 50 \% \text { of } \\
\text { the time. }\end{array}$} & 0 & 10 \\
\hline & & \\
\hline & 40 & 10 \\
\hline & & \\
\hline $\begin{array}{l}\text { the time. } \\
\text { I like a general, theoretical approach } 75 \% \text { of the time } \\
\text { and a concrete, practical approach the other } 25 \% \text { of }\end{array}$ & 40 & 15 \\
\hline the time. & 20 & 30 \\
\hline I like a general, theoretical approach $100 \%$ of the & & \\
\hline time. & 0 & 35 \\
\hline
\end{tabular}

variety of reasons. This situation has been corrected in the third year; students are now furnished with the proper information in advance.

\subsection{Analysis}

Table IV provides a pleasing picture of the course, compared with the usual findings at this school, which on the average are much lower for all the courses and classes in this field of study as a whole. Moreover, columns E and $\mathrm{F}$, reflecting the same year of study (fifth level) confirm this picture, giving the course's teaching methodology a clear show of confidence.

This last comparison actually hides a much more promising findings if we take an in-depth look at Table $\mathrm{V}$, which presents one of the questions posed in the second questionnaire. This table shows that $80 \%$ of the students preferred an education with a concrete and practical approach $50 \%$ or more of the time, an education with a concrete and practical approach $50 \%$ or more of the time, while $65 \%$ believed that this course involved a concrete and practical approach equal to or less than $25 \%$ of the time. (Note: the reaction to this question varies greatly.) Despite this mismatching, which prompts us to believe that the course runs against the current, the "interest of the contents": (see Table IV) is comparable to, and a little above, the rest of the courses normally offered at this level of specialization. 
We have reached the conclusion, through discussion, that such findings do not reflect solely the quality of the professor and the participatory nature of the methodology; rather they suggest the existence of an intrinsic factor that helps to overcome the effects of the initial lack of information and the mismatching of profiles.

We believe that the contents of the course fill a gap in the highly specialized and fragmentary training of our students: the concepts, experience, vision, and approach acquired by studying and managing the term "complexity," tools which are open, comprehensive, and modern, provide engineers with a new perspective that promotes an ordered and more complete consideration of reality.

\section{CONCLUSIONS}

In this paper I have presented and analyzed a 3-year experiment involving a course on complexity and informatics. This course forms part of an attempt to offset the increasingly more specialized curriculum of informatics training.

The experiment reflects the mental trajectory of the author who, with the same aims in mind, introduced the course Cybernetics and Systems Theory into the ETSIT of Madrid's curriculum in 1978. It is this very course that we have been discussing, and whose current contents date back to the 1985-1986 academic year. In keeping with its title, this course formerly centered on cybernetics and systems theory. While the students' reception is now favorable, in the past it has been less satisfactory. We now know the degree to which our students prefer to be more practical than theoretical and have redressed this balance. We have observed how they use the concept complexity in all its forms-provided that we continue to explain lucidly complexity's relationship with the largest possible number of problems in the student's specific field of specialization.

One emerging aspect yet to be assessed is that, unlike the rest of the curriculum, this course seems to stimulate certain aptitudes for creativity and cognitive complexity among students.

The findings taken from student surveys and analyses encourage us to continue with the experiment and to embark on a systematic study to justify, perfect, and strength this effort, making it essential for innovative learning within the field of information technologies in general, and informatics in particular.

This school year we have extended this experiment to the doctoral training level, by starting up research on sociotechnical complexity in the area of office automation. 


\section{APPENDIX}

\section{Bibliography Used for the Course (Academic Year 1985-1986)}

1. Beer, S. (1974). Designing freedom, John Wiley and Sons, London, 1-66.

2. Cabinet Office (1980). Advisory. Council for Applied Research and Development, Information Technology, Her Majesty's Stationery Office, London.

3. Goldschlager, L., and Lister, A. (1982). Computer science. A modern introduction, PrenticeHall, London, 87-106.

4. Illich, I. (1973). La convivencialidad, Barral, Barcelona (Spanish).

5. Klir, G. J. (1985). Complexity: some general observations, Systems Research, vol. 2(2), 131-140.

6. Lasagni, C. (1985). El pensamiento frente al ordenador, Telos, 2, 135-139.

7. Parnas, D. L. (1985). Software aspects of strategic defense systems, American Scientist, 73, September-October, 432-440.

8. Matsumura, T. (1983). Future microprocessor trends, in Mason, R. E. A. (ed.), Information Processing, I.F.I.P./Elsevier Science Publishers.

9. Sàez Vacas, F. (1985). Cinco subculturas informáticas, Telos, 1, 33-37 (Spanish).

10. Sáez Vacas, F. (1983). Las tecnologias de la tercera revolución de la información, Mundo Electrónico, 133, 133-141 (Spanish).

11. Sáes Vacas, F. (1985). Convivencialidad, complejidad, computadores e informática, $L a$ Vanguardia, 24 Febrero, 1985 (Spanish).

12. Sáez Vacas, F. (1983). Facing informatics via three complexity levels, Proceedings of the 10th International Congress on Cybernetics, Namur, 30-40.

13. Sáez Vacas, F. (1984). Propuesta de algunas pautas para guiar la elaboración a mediados de los ochenta, de los objetivos, metodología y pedagogia de la enseǹanza de la informática en cualquier nivel educativo, Papeles de Buitrago, C.R.E.I., Madrid, 10-56 (Spanish).

14. Siewiorek, D., et al. (1982). Computer structures: Principles and examples, McGraw-Hill, N.Y.

15. Warfield, R. W. (1982). The new interface technology, Byte, December, 218-230.

\section{REFERENCES}

Ackoff, R. L. (1974). Redesigning the Future, Wiley, New York.

Ashby, W. R. (1956). An Introduction to Cybernetics, Wiley, New York.

Bartee, Th. C. (ed.) (1985). Data Communications, Networks and Systems, Sams \& Co., Indianapolis.

Beer, S. (1974). Designing Freedom, Wiley, London.

Beer, S: (1975). Platform for Change, Wiley, London.

Boulding, K. E. (1986). The next thirty years in general systems. Gen. Syst. Yearbook XXIX, 3-5.

Flood, R. L. (1987). Complexity: A definition by construction of a conceptual framework. Syst. Res. 4(3), 177-185.

Hirschheim, R. A. (1985). Office Automation. A Social and Organizational Perspective, Wiley, Chichester.

Illich, I. (1973). Tools for Conviviality, Harper \& Row, New York.

Klir, G. J. (1969). An Approach to General Systems Theory, Van Nostrand Reinhold, New York. Matsumura, T. (1983). Future microprocessor trends. In Mason, R. E. A. (ed.), Information Processing, IFIP/EIsevier, Amsterdam. 
Morin, E. (1977). La Méthode: La Nature de la Nature, Seuil, Paris.

Sáez Vacas, F. (1983a). Facing informatics via three-level complexity views. In Lasker, G. E. (ed.), Proceedings of the 10th International Congress on Cybernetics, Symposium XII: Man in a High Technology Environment, International Association of Cybernetics, Namur.

Sáez Vacas, F. (1983b). Las tecnologías de la tercera revolución de la información. Mundo Electrónico. 133, 133-141.

Sáez Vacas, F. (1984). Some framework ideas for software engineering education. In Chow, L. R. (ed.), Proceedings of International Computer Symposium, Tamkäng University, Taiwan.

Sáez Vacas, F. (1987a). Towards a conceptual remodeling of information technologies based on a broad consideration of complexity. Proceedings of the 31st Annual Meeting of the International Society for General Systems Research, Budapest.

Sáez Vacas, F. (1987b). Computadores Personales: Hacia un Mundo de Máquinas Informáticas, Fundesco, Madrid.

Simon, H. A. (1970)! The Sciences of the Artificial, MIT Press, Cambridge, Mass.

Torrero, E. (ed.) (1985). Next-Generation Computers, Spectrum Series, IEEE Press, New York. 